\title{
Результаты обработки геологических стресс-индикаторов для доголоценовых землетрясений Кандалакшского района
}

Гордеев Н.А., Клоков И.А., Стрельников А.А.

ИФ3 РАH, Москва, gord@ifz.ru, ilia.klokov@mail.ru,aas@ifz.ru

Аннотация. На сегодняшний день активно обсуждаются вопросы сейсмической опасности Балтийского кристаллического щита, который характеризуется слабой современной сейсмичностью, как и другие платформы. Данный регион интересен тем, что здесь около 12 тыс. лет назад растаял мощный покровный ледник, и после резкого снятия нагрузки стали возникать систематические сильные землетрясения.

Так одним из сейсмически активных участков является зона Кандалакшского грабена. С начала инструментальной регистрации землетрясений, здесь было выявлено более 40 сейсмических событий с магнитудой до 5.

В 2019 году во время комплексной сейсмологической экспедиции в рамках уточнения сейсмической опасности Кандалакшского грабена нами было изучено несколько крупных локаций на территории Чупинской губы и прилегающих окрестностей. Были поставлены следующие задачи: 1) Поиск и фиксация сейсмогенных нарушений рельефа в Северной Карелии; 2) Составление карт-схем распространения сейсмодислокаций; 3) Определение параметров палеоземлетрясений; 4) Определение современных зон напряжений.

Ключевые слова: Керетский архипелаг, о.Сидоров, о.Пежостров, палеосейсмология, тектонофизический анализ.

\section{Results of the analysis of geological stress indicators for pre-Holocene earthquakes in the Kandalaksha region}

Gordeev N.A., Klokov I.A., Strelnikov A.A.

IPERAS,Moscow,gord@ifz.ru,ilia.klokov@mail.ru,aas@ifz.ru

Annotation. Today, the issues of the seismic hazard of the Baltic crystalline shield, which is like other platforms characterized by weak modern seismicity, are being actively discussed. This region is interesting because a powerful ice sheet melted here about 12 thousand years ago, and after a sharp removal of the load, systematic strong earthquakes began to appear.

One of the seismically active areas is the Kandalaksha graben zone. Since the beginning of instrumental registration of earthquakes, more than 40 seismic events with a magnitude of up to 5 have been identified here.

In 2019, during a complex seismological research expedition, as part of clarifying the seismic hazard of the Kandalaksha graben, we studied several large locations in the Chupinskaya Bay and adjacent environs. The following tasks were set: 1) Search and fixation of seismogenic relief disturbances in North Karelia; 2) Drawing up maps of seismic dislocation propagation; 3) Determination of parameters of paleoearthquakes; 4) Calculation of modern stress zones.

Key words: Keret archipelago, Sidorov Island, Pezhostrov Island, paleoseismology, tectonophysical analysis

\section{Введение}

При подготовительных работах путем дешифрирования космоснимков нами были выделены объекты интереса (отмеченные красными рамками), при этом предпочтение отдавалось возвышенным скальным массивам, называемым бараньими лбами и имеющим сглаженный волнистый или грядовый рельеф за счет избирательной ледниковой обработки, где отсутствует чехол рыхлых осадков с видимыми из космоса линейными разрывными нарушениями.

Далее по району Керетского архипелага (рис. 1) были рассмотрены выявленные нарушения рельефа. В первую очередь это трещины и расселины тектонического характера. В гранитогенейсовых массивах достаточно редки трещины, имеющие вероятно тектоническое происхождение. Раскрытые тектонические трещины обнаружены нами в районе о. Покормежный.

Следующий тип нарушений - предполагаемые сейсмотектонические рвы, которые образуются подобно микрограбенам, заполненным раздробленными блоками или задернованными угловатыми обломками. 


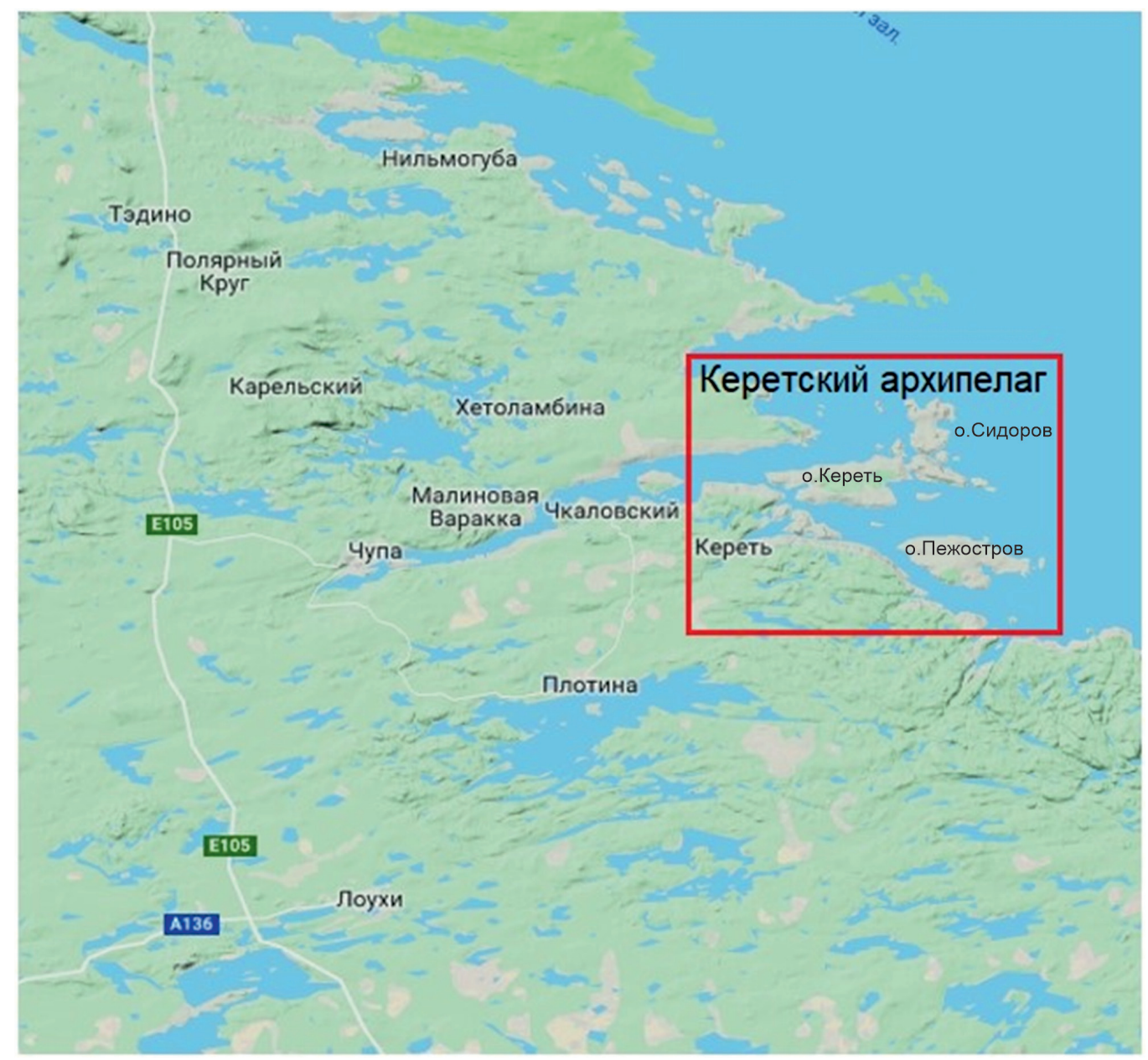

Рис. 1. Район исследования. Керетский архипелаг.

Fig. 1. Study area. Keret archipelago.

На вершинах бараньих лбов были обнаружены примеры площадного раздробления пород или каменные развалы, в том числе обнаружена наброшенная глыба, говорящая о сильном ударе снизу.

Также выявлялись области существенного раздробления скальных уступов.

\section{Описание признаков доголоценовых сейсмодислокаций}

В ходе серии маршрутов был подтвержден ряд тектонических нарушений и форм рельефа предположительно сейсмотектонического происхождения - структурно-тектонические рвы, участки повышенной трещиноватости, скальные уступы, «каменные хаосы».

Для Пежострова характерны волнистые и слабонаклонные поверхности, оглаженные ледником, сложенные архейскими гнейсами и амфиболитами, пронизанными интрузиями основного и кислого состава, без рыхлого чехла. Они расположены на высотах 35-38 метров вразных частях острова, слабо изменяясь по высоте по всему острову. Немного заметно увеличение высоты с востока на запад.

Для острова характерны не самые крутые уклоны (не более 7 градусов). Но на юге острова путем исследования ЦМР был обнаружен уступ, вероятно, тектонического происхождения. Склоны северной и южной экспозиций примерно одинаковой крутизны. На северном побережье острова имеются сейсмодислокационные структуры: тектонические рвы, зоны трещиноватости, установленные геолого-геоморфологическими методами (рис. 2.1). Характерна слабая плотность сейсмодислокаций на острове, но общая парагенетическая сгруппированность, а также разное простирание сейсмодислокаций (Башенина, 1960; Воскресенский, 1971; Спиридонов, 1958). 


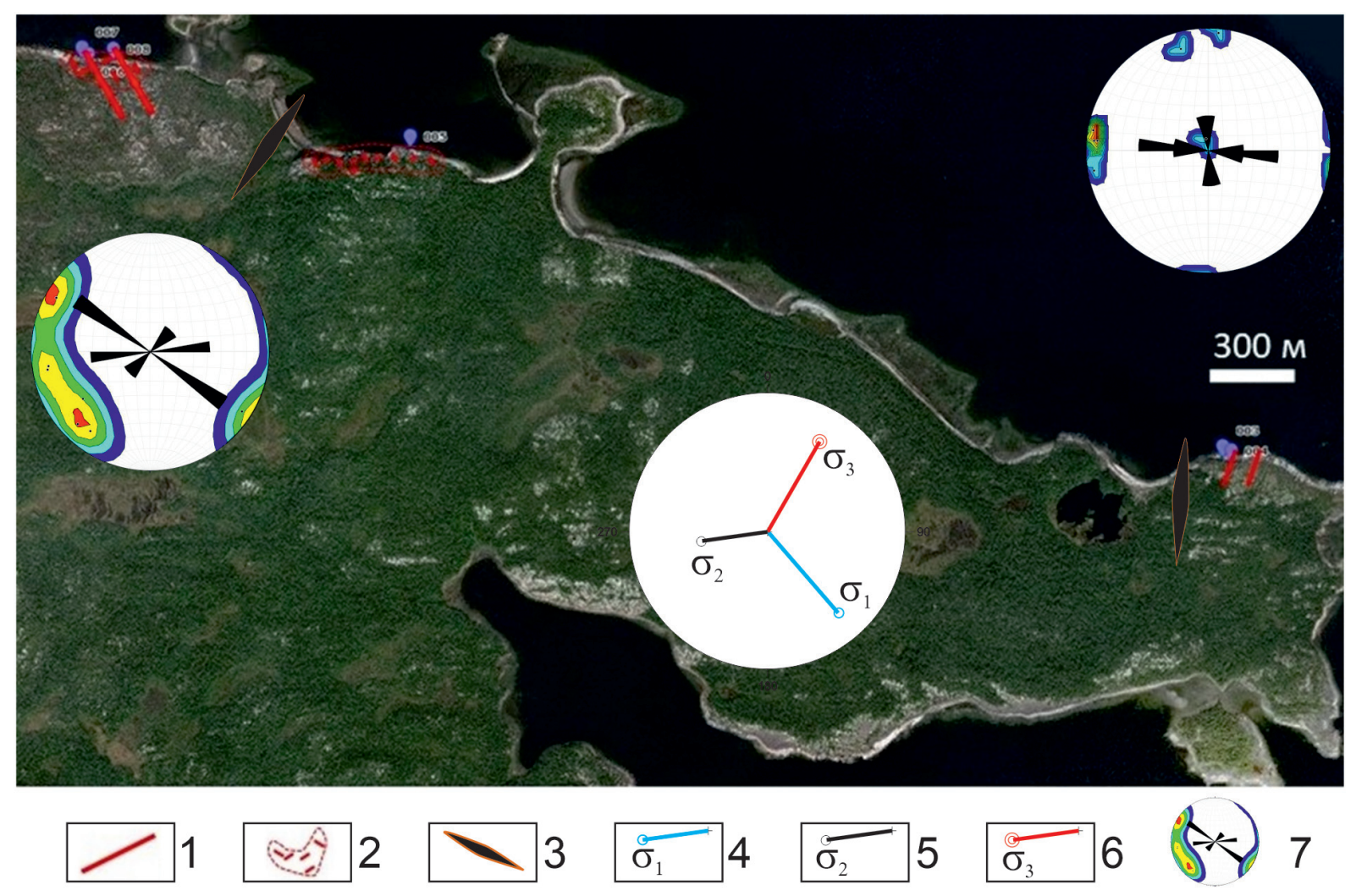

Рис. 2.1. Северное побережье о. Пежострова. 1 - структурно-тетконические рвы; 2 - зоны трещиноватости; 3 - максимум по простиранию трещин; 4-6 - расчет по МКА (Ребецкий, 2017) (на верхнюю полусферу): 4 - ось растяжения, 5 - промежуточная ось, 6 - ось сжатия; 7 - расчет по stereonet, плотность по полюсам трещиноватости (на верхнюю полусферу).

Fig. 2.1. North coast of island Pezostrov. 1 - structural tetconic ditches; 2 - fracture zones; 3 - maximum along the strike of fracture; 4-6 - calculation according to MKA (Rebetsky, 2017) (on the upper hemisphere): 4 - tension axis, 5 - intermediate axis, 6 - compression axis; 7 - calculation by stereonet, density by fracture poles (to the upper hemisphere).

Морские цокольные и аккумулятивные террасы расположены на северном и восточном берегах высотой до 1 метра и 3-4 метра соответственно. Более древняя морская терраса высотой 25-39 м занимает почти весь центр острова. Это доказывает современный подъем Балтийского щита. Высота морских террас увеличивается с запада на восток (Башенина, 1960; Спиридонов, 1958)

Пежостров представляет собой единый блок, так как:

- высоты на острове примерно одинаковы, что можно говорить о единстве развития.

- уклоны северной и южной экспозиции примерно одинаковы, что говорит о едином цикле развития;

- особенности расположения и развития морских террас говорит нам о том, что остров представляет единый блок: в разных частях острова высотное положение древних террас относительно одинакова;

- надо упомянуть о присутствующем рядом глубоководном разломе, который был визуализирован благодаря геоинформационным технологиям, который является генератором развития блокового процесса;

Обобщенный тектонофизический анализ показал, что на территорию о.Пежострова распространяется глобальное растяжение со сдвигом (по результатам расчёта МКА (Ребецкий, 2017)). Трещиноватость развивается преимущественно в С-С-В румбах по простиранию, подчёркивая простирание таких крупных структур, как структурно-тектонические рвы. Интересным фактом является то, что территория испытывает сжатие в С-В простирании. 
Остров Сидоров по своему строению несколько отличается. На нем тоже преобладают волнистые и слабонаклонные поверхности, оглаженные ледником, которые расположены на высотах 30-54 метров (в разных частях острова). Опущена центральная часть острова, подняты юго-восток, юго-запад, северо-восток, северо-запад (рис. 2.2)

Для острова характерны не самые крутые склоны, не более 8 градусов, хотя есть и более крутые участки. На юго-востоке и северо-западе острова обнаружены уступы, предположительно сейсмотектонические. Стоит отметить разный уклон прибрежных склонов по всем частям острова (Башенина, 1960; Воскресенский, 1971; Спиридонов, 1958).

Прибрежная терраса высотой 3-4 метра обнаружена на юге острова. По острову распространены остатки более древних морских террас (они находятся на большей высоте): в том числе самая крупная, расположенная в центре острова на высоте более 12 метров, остальные расположены выше 20 метров. Заметно, что в центре острова расположен самый обширный фрагмент морской террасы (высота более 16 метров), а по юго-восточному, юго-западному, северо-восточному, северо-западному частям острова расположены более высокие и древние террасы (Башенина, 1960; Воскресенский, 1971; Спиридонов, 1958).

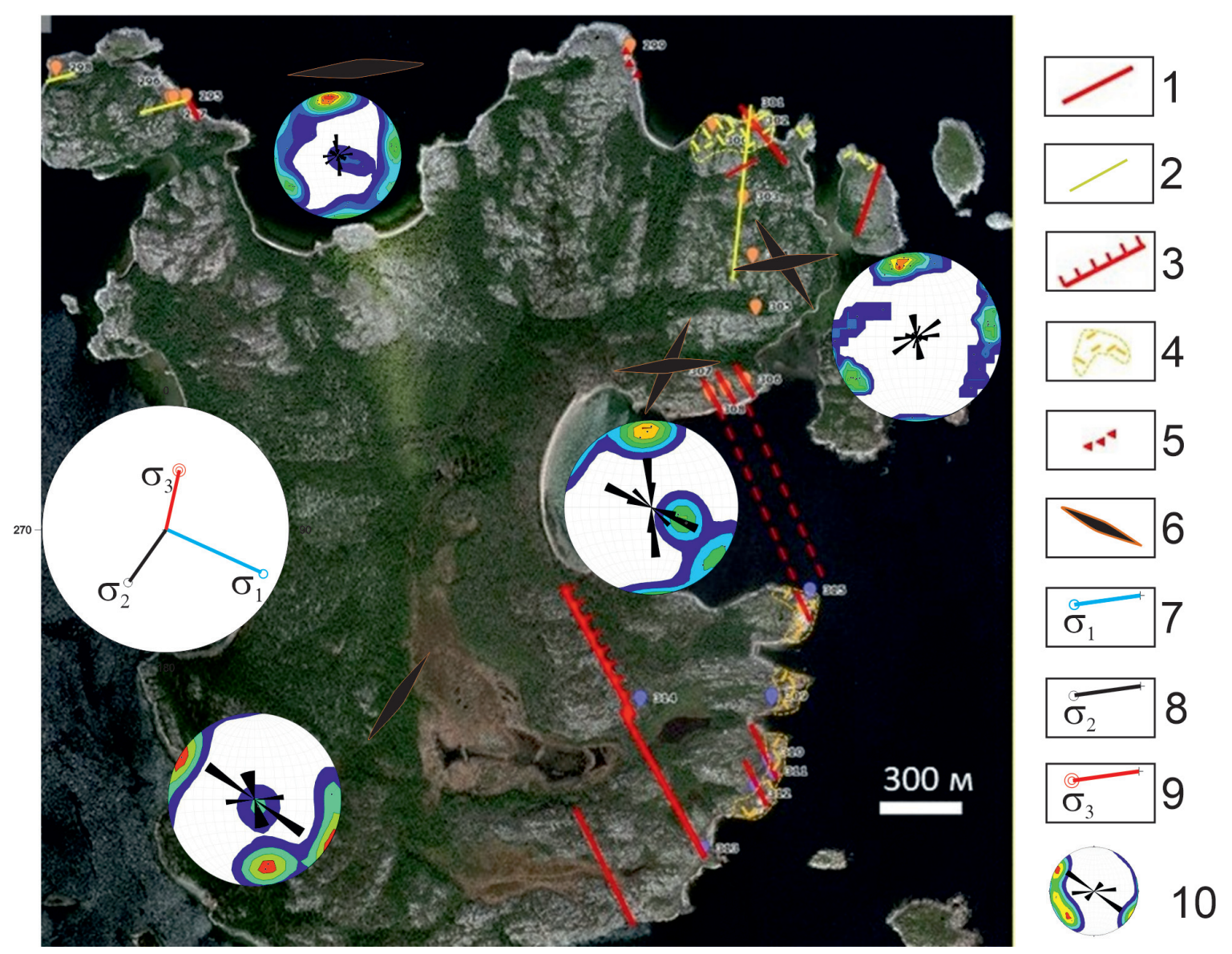

Рис. 2.2. о.Сидоров. 1 - молодые разрывы в виде трещин и рвов с неоглаженными бортами; 2 - древние разрывы с оглаженными бровками; 3 - предполагаемый сбросовый уступ; 4 - зоны трещиноватости; 5 - глыбовые развалы; 6 - максимум по простиранию трещин; 7-9 - расчет по МКА (Ребецкий, 2017) (на верхнюю полусферу): 7 - ось растяжения, 8 - промежуточная ось, 9 - ось сжатия; 10 - расчет по stereonet, плотность по полюсам трещиноватости (на верхнюю полусферу).

Fig. 2.2. island Sidorov. 1 - young ruptures in the form of cracks and ditches with unfinished sides; 2 - ancient breaks with ironed edges; 3 - prospective fault scarp; 4 - fracture zones; 5 - block breakdowns; 6 - maximum along the strike of fracture; 7-9 - calculation by MKA (Rebetsky, 2017) (on the upper hemisphere): 7 - tension axis, 8 - intermediate axis, 9 - compression axis; 10 - calculation by stereonet, density by fracture poles (to the upper hemisphere). 
Характер трещиноватости удалось проанализирвоать на центральную и северо-восточную часть острова. Общий тренд развития трещин выделить не удалось, так как на краевом обнажении северо-восточного блока имеет главный тренд простирания $130 \pm 10$, а центральный участок характеризуется $50 \pm 10$, что также подтверждает неоднородное строение острова Сидоров.

По обобщенному расчету МКА (Ребецкий, 2017) по трем точкам имеем геодинамический тип растяжения со сдвигом. А ось сжатия и растяжения простираются на север-северо-восток, юговосток соответственно. Подобные характеристики позволяют нам утвердить подавляющее количество откартированных сейсмодислокаций, как структурно-тектонические рвы и грабены.

На восточном побережье острова обнаружены сейсмодислокационные структуры: тектонические рвы, зоны трещиноватости, установленные геолого-геоморфологическими методами (рис. 2.2).

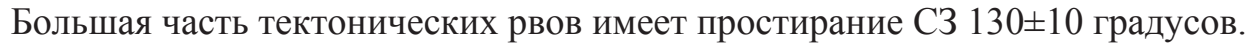

Обнаружена парагенетическая сгруппированность сейсмодислокаций на восточном побере-

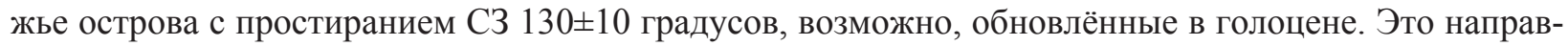
ление практически совпадает с простиранием основных сбросов Кандалакшского грабена, расположенных в акватории. Можно предположительно сказать о сильном землетрясении в голоцене, который породил эти сейсморазрывы, эпицентр которого, предположительно, расположен в разломе восточнее острова.

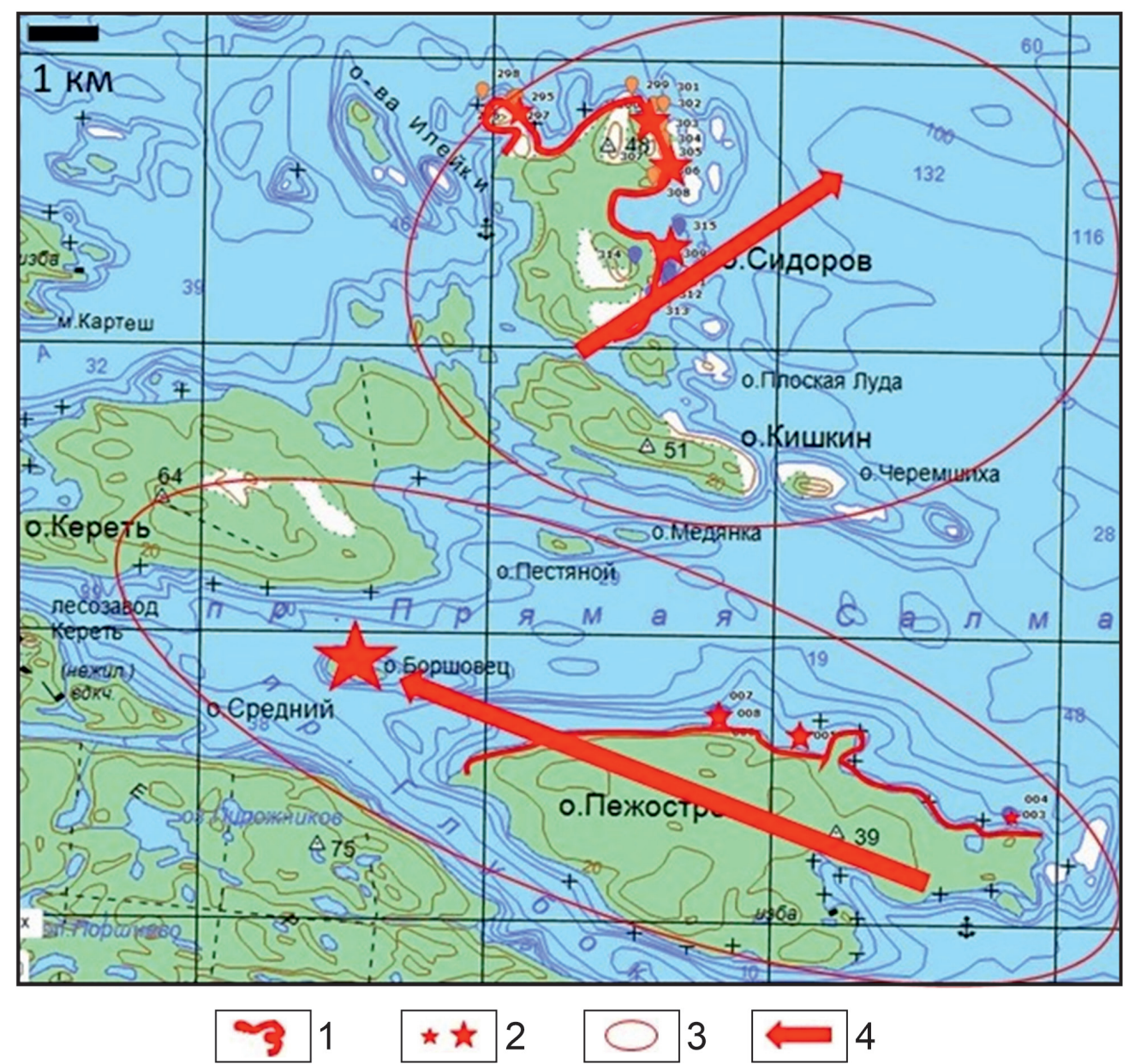

Рис. 3. Общая схема распространения предполагаемых сейсмодислокаций Керетского архипелага. 1 - обследованное побережье; 2 - предполагаемые вторичные сейсмодислокации; 3 - возможные ареалы их распространения; 4 - направления уваеличения интенсивности сейсмического воздействия.

Fig. 3. General scheme of the distribution of the supposed seismic dislocations of the Keretsky archipelago. 1 - surveyed coast; 2 - prospective secondary seismic dislocations; 3 - possible areas of their distribution; 4 - directions of increasing the intensity of seismic impact. 
О. Сидоров представляет собой скопление из нескольких микроблоков: юго-западного, юговосточного, северо-западного, северо-восточного простираний. Об этом говорят:

- высоты разных частей острова разные, как и уклоны склонов;

- особенности расположения морских террас: разная высота террас говорят о том, что остров представляет скопление нескольких блоков: абсолютно разное высотное положение морских террас в разных частях острова говорят о разном развитии разных частей острова, а большая низкая морская терраса в центре на фоне высоких террас по краям подтверждает этот вывод.

\section{Заключение}

Ввиду слабой обеспеченности фактическим материалом можно сделать только локальные выводы по территории Керетского архипелага (рис. 3):

1. Некоторые разрывы на Пежострове образовались благодаря землетрясению, которое произошло в голоцене, с эпицентром между Пежостровом и Боршовцом;

2. Можно предположительно сказать о сильном землетрясении в голоцене, которое породи-

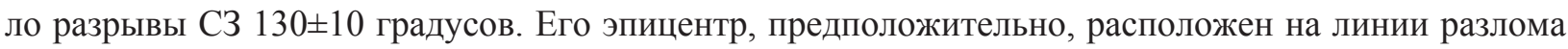
северо-восточнее острова;

3. Пежостров представляет собой единый блок, в то время как о. Сидоров представляет собой скопление из четырех микроблоков.

4. Общий тектонофизический анализ показал, что структуры о.Сидоров и о.Пежостров образовались при геодинамическом режиме растяжения со сдвигом, что позволяет нам утверждать, что найденные структуры являются структурно-тектоническими рвами или грабенами.

5. Рассчитанные оси сжатия для островов имеют север-северо-восточное простирание, что является своеобразным дополнительным указанием на единую природу их развития. Они развиваются в едином поле напряжения.

Таким образом, мы предполагаем, что изученные структуры являются сбросово-сдвиговыми разрывами младшего ранга к Кандалакшскому грабену.

\section{Литература}

1. Башенина Н.В. Легенда геоморфологической карты Советского союза (масштаба 1:25000-1:50000)/ Сост и подг. к изд. Московский Государственный Университет Географический факультет

2. Воскресенский С.С. Динамическая геоморфология. Формирование склонов. М. Изд-во: Моск. ун-та, $1971.229 \mathrm{c}$.

3. Геологическая карта СCCP. Карельская серия Q-36-XVI. / Сост и подг. к изд.Министерством геологии охраны недр СССР, 1:200000. Петрозаводск. 1959 .

4. Информационный картографический ресурс (Электронный ресурс)-официальный сайт. Режим доступа: https://nakarte.me/ (дата обращения 22.09.2020).

5. Отчеты о поисковых и геологоразведочных работах в районе Лоухского район.

6. Ребецкий Ю.Л., Сим Л.А., Маринин А.В. От зеркал скольжения к тектоническим напряжениям. Методы и алгоритмы. Москва. Изд-во: ГЕОС. 2017. 225 с.

7. Спиридонов А.И. Вопросы составления геоморфологических карт при среднемасштабной комплексной геологической съемке северных районов. Ленинград. 1958. 